\title{
TRANSFERÊNCIA DE INFORMAÇÃO E ConHeCimento nas Cadeiasde AutopeÇas ElÉtricasde Reposição e Perfisde Alumínio PARA CONSTRUÇÃo CIVIL: UM ESTUdO COMPARATIVO
}

\author{
Marco Antonio Pinheiro da Silveira \\ DaitoremAdministracãopdaEAESP/ FGV , Pós \\ DautaradoemAdministraçãopdaFEA/ USP, \\ Professar doPrograma deMestradbemAdministração \\ daUniversidadeMuniapal deSãoCadanodbSul \\ marcopinhero@ussedu.br
}

Flavio Corrêa Rangel

MestrandodoProgramadeMestradoemAdministracãa daUnivesidadeMuniajpal deSãoCadanodbSul, Professorda UniversidadeNouedeJulho- UNINOV E flaviarangi@gdbacam

Marcos da Silva Travassos

MestrandbdoProgramadeMestradoemAdministracão daUnivesidadeMuniapal deSãoCadanodbSul marcostravassos@hatmiil.cm
RESUMO

E ste trabalho objetivou identificar como se dá atualmente a troca de informações e conhecimento entre elos de duas cadeias de suprimentos brasileiras: autopeças elétricas de reposição ou aftemarkete perfis de alumínio extrudado para construção civil, aos quais vamos nos referenciar respectivamente como cadeia de autopeças e cadeia do alumínio. Trata-se de um estudo exploratório de natureza qualitativa, em que foram realizadas 15 entrevistas com profissionais dos diferentes elos. O bservou-se que a cadeia de alumínio realiza mais troca de conhecimento do que a de autopeças. Na cadeia de autopeças predomina a troca de informações sobre necessidades de mercado, enquanto na de alumínio predomina a transferência de informações técnicas relativas a produto. Há equilíbrio na utilização de meios estruturados e não estruturados para a transferênciade informações.

Palavras-chave: Transferência de Conhecimento. Cadeia de Suprimentos. G estão do Conhecimento. Autopeças de Reposição. Alumínio para Construção Civil.
This study's digetive was identifyinghowties of two Brazilians supply dhains exhangeinformation and knowkedge deetrical auto parts, aftemarke network, andaluminumused for building construction network. It was a qualitativeexploratory reserch, in whidh 15 interviens with workers from thedifferent ties wereused Wefaund that theeismmreknowkedge exdhangein aluminumdhain than in autoparts. In auto parts dain preedominateinformation exdhangeabout market neeessities whilein aluminumdain predominatetechnical infomation transfer about product. There is balancein dhannds used for transference- structured and no structured.

Key words: KnovkeegeTransfe. ValueChain Knowkedge Management. AutopartsAftemarke. Aluminiumfor Civil Construation. 


\section{INTRODUÇÃO}

Uma questão fundamental ligada à pesquisa em estratégiaé identificar a razão por que as empresas têm performances diferentes. Para responder a essa questão, pesquisadores frequentemente trataram empresas como entidades autônomas. A pesquisa em estratégia normalmente não observou as diferenças de lucratividade decorrentes da participação de empresas em redes estratégicas. Mais recentemente, tem sido adotada a abordagem de redes, que considera que a performance de uma empresa pode ser fortemente influenciada pelos elos interempresa (DY ER; HATCH, 2006).

Gulati (1999) considera que uma rede de empresas pode oferecer "recursos de rede que são fonte de informações valiosas para as empresas". De maneira similar, Dyer e Singh (1998) identificaram rotinas de compartilhamento de conhecimento como uma das quatro fontes possíveis de "rendas relacionais" - que são lucros gerados numa relação de troca, que não poderiam ser gerados por uma empresa isolada. O s autores definem rotina decompartilhamento deconheimento como "um padrão regular de interações entre empresas que permite a transferência, recombinação, ou criação de conhecimento especializado".

Probst etal (2002) consideram que as empresas importam uma parte substancial de seu conhecimento de fontes externas, seja de clientes, fornecedores, concorrentes ou parceiros. Essas relações cooperativas - apesar do considerável potencial - são raramente utilizadas em sua totalidade, e levam as empresas a adquirir o conhecimento que não conseguem desenvolver por si mesmas. O monitoramento das competências de fornecedores e prestadores de serviços tem se tornado, em função do processo de terceirização, um fator importante, já que as políticas de gestão enxuta têm levado empresas a terceirizarem parte de suas competências essenciais. A interação das empresas com seus ambientes de conhecimento expõem suas lacunas e déficits de conhecimentos e habilidades internas. $O$ benchmarking externo também pode levar à identificação das melhores práticas. A Figura 1 demonstra as lacunas de conhecimento a serem transpostas. A lacuna 1 pode ser transposta através da aquisição do conhecimento seja por recrutamento, cooperação ou imitação, porém raras vezes cria competências organizacionais difíceis de serem imitadas. A lacuna 2 é a de mais difícil transposição, pois depende do desenvolvimento de um conhecimento ainda não existente através de pesquisas, estudos de mercado, círculos de qualidade.

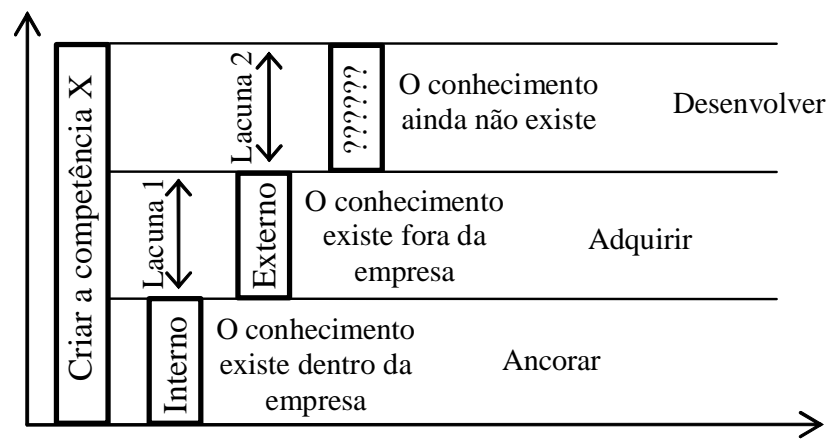

Figura 1: Tipos de Lacuna de Conhecimento

Fonte: Probst et al. (2002).
Assim, uma importante questão a ser observada pelas empresas atualmente é a forma como elas se relacionam com as outras empresas, e ainda quais as trocas de informação e conhecimento realizadas entre elas. A questão é também extremamente interessante sob o ponto de vista da pesquisa acadêmica. Identificar os padrões de relacionamento e de troca de conhecimento em cadeias produtivas pode trazer subsídios para a busca de melhoria de performance das empresas e da cadeia em si.

Este trabalho consistiu de um estudo exploratório no qual foi analisado o processo de transferência de informação e conhecimento de duas cadeias produtivas distintas: a cadeia de autopeças elétricas voltada para a fabricação de peças de reposição e a cadeia de alumínio voltada para o fornecimento de esquadrias para o setor de construção civil. Foram pesquisados três elos dessas cadeias - indústria, distribuidor e aplicador. Um aspecto particularmente importante no estudo da transferência de conhecimento nas cadeias consiste em verificar em que medida os conhecimentos adquiridos pelos elos que têm contato direto com o consumidor final - autoelétrico e serralheiro, em grande parte empresas de pequeno porte - chegam e são aproveitados pelo elo mais forte, a indústria. Pode-se considerar que seria importante essa transferência, visto que os aplicadores efetivamente manuseiam os produtos e têm feedbadk dos consumidores. Mas é também relevante averificação da ocorrência da transferência do conhecimento no outro sentido, da indústria em direção ao aplicador, passando pelo distribuidor.

0 problema de pesquisa que este trabalho se propôs a estudar pode ser expresso pela seguinte questão: Como os elos indústria, distribuidor e aplicador das cadeias produtivas brasileiras de autopeças de reposição e de perfis de alumínio para construção civil estão realizando troca de informação e de conhecimento? As duas cadeias têm características distintas, mas têm elos comuns - indústria, distribuidor e aplicador.

O objetivo do trabalho, por sua vez, consistiu em identificar a percepção de profissionais dos elos indústria, distribuidor e aplicador com relação à existência de transferência de informação e de conhecimento entre os elos dessa cadeia como se dá esse processo, quais os principais conhecimentos/ informações transferidos e quais os principais canais/ meios utilizados para a transferência.

\section{TEORIA}

\subsection{Redes deE mpresas}

A renovação do interesse pela perspectiva das redes se dá principalmente devido ao surgimento e à ascensão de pequenas empresas empreendedoras em diferentes atividades e circunstâncias (região central da Itália, Vale do Silício, Japão, Coreia), com fortes relações verticais e horizontais, em substituição à pequena empresa verticalmente integrada (NOHRIA, 1992).

Gulati, Nohria, Zaheeer (2000) apresentam definição de redes de empresas: são elos interorganizacionais duradouros, que têm significação estratégica para as empresas. Incluem alianças estratégicas, jaintventures relações de parceria compradorfornecedor de longo prazo. Esses autores chamam a atenção para 0 fato de que as redes têm também um lado negro, à medida que fecham as portas para alguns. 
Alguns autores discutem a lógica de formação das redes, ou as razões que levam as empresas a estabelecerem essas ligações duradouras. Fleury e Fleury (2005) consideram que a arquitetura das redes é função do domínio do conhecimento. Para os autores, 0 acervo de conhecimento de uma empresa, ou o tipo de competências que domina, determina sua posição relativa nesses arranjos.

De acordo com Ahuja (2000), três formas de capital acumulado podem influir para o estabelecimento de redes - capital técnico, capital comercial e capital social - e as empresas que possuem estoques desses capitais conseguiriam vantagens na formação de ligações. Porém, empresas que não têm esses recursos acumulado também poderiam, segundo o autor, formar ligações, se elas geram quebras tecnológicas radicais. Ahuja (2000) define os três tipos de capitais:

Capital técnico - Equipamento caro, pessoal qualificado, investimentos altos (inovação). Nem todas as empresas podem fazê-lo, e as que 0 fazem tornam-se atrativas. Capital comercial - Converter inovações técnicas em produtos e serviços requer capacidades de manufatura e marketing, além de ativos como fábricas e redes de distribuição. Pode ser caro, e quem tem é também atrativo. Capital social - Influências sociais estruturais, ntwork resarces D ifere do capital técnico e comercial.

A classificação proposta por Ahuja (2000) suscita questionamento sobre possível inter-relação entre o aspecto da regionalidade e do capital social.

Enquanto os modelos de Fleury e Fleury (2005) e, A huja (2000) se concentram na lógica da formação de redes, Holm et al (2000) utilizam uma abordagem que analisa a interdependência em relacionamentos de negócio que estão em andamento. Esses autores desenvolvem um modelo que examina se a rede de negócio circunjacente e os relacionamentos entre os parceiros afetam a interdependência desses parceiros, e se a interdependência influencia a criação de valor no relacionamento de negócio. Esse modelo está representado na Figura 2.
No modelo de Holm et al. (2000), os relacionamento entre empresas estratégias cooperativas se apoiam em "troca de comprometimentos". Os autores mencionam modelo de Anderson e Weitz (1992), que investigaram como fabricantes e distribuidores interativamente construíram e sustentaram o comprometimento em seus relacionamentos. 0 modelo, que segundo os autoresé suportado empiricamente, coloca que cada comprometimento de uma empresa é influenciado pela sua percepção do comprometimento da outra empresa. "Fazendo promessas, uma empresa demonstra comprometimento, que a outra parte responde fazendo promessas", afirmam os autores. Assim, Holm et al. (2000) elaboram hipóteses (confirmadas pelo estudo) de que (1) a dependência mútua tem efeito positivo na criação de valor no relacionamento, e (2) o comprometimento mútuo entre parceiros tem efeito positivo na dependência mútua.

- A dependência mútua é definida pelos autores como a força de uma relação de dependência balanceada entre parceiros. (No constructo da dependência mútua, os autores utilizam como indicador para a dependência mútua a questão "qual seria o efeito para o negócio de sua empresa se vocês perdessem este parceiro").

- O comprometimento mútuo é definido como o interesse de ambos os parceiros em fazer sacrifícios de curto prazo para atingir benefícios de longo prazo no relacionamento. (No constructo do comprometimento mútuo, os autores utilizam como indicador para o comprometimento mútuo a questão "quão grande é o investimento feito por sua empresa neste seu relacionamento").

Holm et al. (2000) consideram ainda que, apesar de os relacionamentos de negócio serem entidades distintas (podendo ser analisadas de forma isolada), eles podem ser melhor entendidos se olhados no contexto. 0 conceito de redes de negócios, segundo os autores, sugere que a coordenação de atividades entre dois parceiros em um relacionamento de negó-

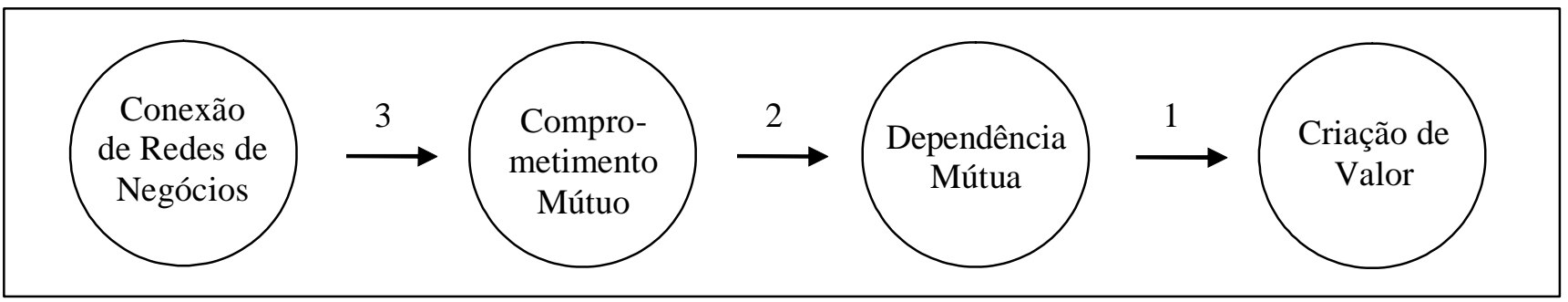

Figura 2: Modelo estrutural de relações entre criação de valor no relacionamento, dependência mútua, comprometimento mútuo e conexão de rede de negócio.

Fonte: Holm et al. (2000).

A ideia chave colocada por Holm et al. (2000) é a de que relacionamentos implicam que os parceiros coordenem um número de atividades de comércio e produção de uma forma que aumenta sua interdependência, e por meio disso sua produtividade conjunta e criação de valor no relacionamento (setas 1 e 2). Como segunda ideia, eles consideram que a coordenação é afetada pelo contexto de rede do relacionamento (seta 3). cio pode também ocorrer dentro do contexto mais amplo da rede de negócios. Uma terceira hipótese do estudo de Holm et al. (2000) é a de que (3) conexões de redes de negócios têm efeito positivo no comprometimento mútuo entre parceiros. O u seja, o fato de a empresa estar inserida numa rede de relacionamentos mais ampla seria favorável à ocorrência de comprometimento mútuo. 


\subsection{Transferência de conhecimento}

Inserida no contexto de redes de empresas e cadeias de suprimentos, a transferência de conhecimento entre empresas é fator relevante na busca de competitividade.

Segundo Chopra e Meindl (2004), uma cadeia de suprimentos consiste no atendimento das requisições dos clientes por todas as partes envolvidas, direta ou indiretamente. Os dois fluxos da cadeia de suprimentos mais comumente citados na literatura são os fluxos de produtos e informações. No âmbito do fluxo de informações, dois elementos têm destaque: a comunicação e os recursos que apoiam essa comunicação (CUNHA; ZWICKER, 2008, p. 149).

De acordo com Mohre Nevin (1990), a comunicação pode ser considerada como a cola que mantém um canal de distribuição unido. A comunicação possui várias facetas que, combinadas, determinam a estratégia da comunicação. Algumas das facetas da comunicação são a periodicidade, o conteúdo compartilhado (tipo de informação), o meio ou canal de comunicação (pessoal, telefone, fax, e-mail, sistemas informatizados), aspectos da comunicação geral (formalidade, regras e procedimentos no processo de comunicação) e o feedback (comunicação bidirecional). São considerados nos modelos estudados na presente pesquisa: a periodicidade, o conteúdo compartilhado, a comunicação geral e 0 feedback. Tais variáveis foram escolhidas depois de diversas entrevistas com integrantes da Empresa Alfa, que as julgaram as mais importantes no que tange ao relacionamento da empresa com seus fornecedores.

O estudo realizado por Dyer e Hatch (2006) examina 0 papel dos recursos de conhecimento da rede em influenciar a performance da empresa. 0 s autores procuram responder à seguinte questão: Pode uma empresa que usa rede de fornecedores idêntica à de seus competidores e compraitens similares das mesmas plantas obter vantagem competitiva através da rede? 0 estudo se voltou para fornecedores de autopeças dos EUA que vendem tanto para a Toyota como para montadoras americanas. $\mathrm{O}$ estudo identificou que o maior compartilhamento de conhecimento da Toyota resultou de uma taxa mais alta de aprendizado dentro das operações de manufatura dos fornecedores voltadas para a Toyota, e que entre 1990 e 1996 os fornecedores de autopeças reduziram defeitos em $50 \%$ para a Toyota contra $26 \%$ para seus maiores clientes americanos. Segundo Dyer e Hatch, 2006, as diferenças de qualidade persistiram nos fomecedores por causa das rotinas interorganizacionais da G M, Ford e Chrysler, que funcionavam como barreiras para a transferência de conhecimento nas plantas dos fornecedores. 0 estudo demonstrou que recursos de rede influenciam a performance da empresa. Também descobriram que alguns recursos e capacidades da empresa são específicos da relação e não são facilmente transferíveis para outros compradores ou redes.

Dyer e Hatch, 2006, enviaram questionário para os gerentes de fábrica. As questões se referiam ao componente de maior valor em U\$ para a Toyota e o mesmo componente para seu maior OEM dos EUA. As variáveis utilizadas naquele estudo são apresentadas no Q uadro 1.

\section{MEDIDAS O PERACIO NAIS}

- Tempo gasto em transferência de conhecimento Número de dias por ano em que o pessoal da montadora e do fornecedor se encontraram face a face pra trocar informações técnicas na fábrica dofomeeedr(Variável FaceD ays)

- Assistência para qualidade Em que medida receberam assistência para qualidade (Var. Q ualityA ssistance likert)

- Assistência para Custo/ estoque Em que medida cada cliente forneceu assistência para estoque (Inventory assistance likert)

VARIÁVEIS DE PERFORMANCE (relacionadas à qualidade do produto e níveis relativos de estoque para cada cliente)

- Qualidade do produto Número de peças defeituosas por milhão da fábrica para cada cliente (Var. D efects)

- Custos com estoque Estoques (matérias-primas, material em processo e produto acabado) diretamente atribuíveis a cada cliente como uma porcentagem das vendas para aquele cliente (Var. Inventory/ sales) testaram com contador em alguns

Quadro 1: Variáveisutilizadas no estudo de Dyer e Hatch (2006) para identificar se a transferência de conhecimento interfere na performance das empresas

Fonte: Elaborado pelos autores.

Assim, o estudo de Dyer e Hatch (2006), verificou se a performance dos fomecedores de autopeças era diferente quando o cliente era a Toyota, em função de diferentes níveis de transferência de conhecimento, o que foi confirmado na pesquisa.

O utro estudo fomece subsídiosimportantes sobre o tema transferência de conhecimento. G iannakis (2008) analisa como um programa de desenvolvimento de fornecedor (SD programmes) pode ser adaptado para criarvalor para as organizações por meio da geração e transferência de conhecimento entre parceiros da cadeia de suprimentos. A abordagem de Giannakis (2008) se baseia na literatura existente sobre desenvolvimento de fomecedor, transferênciade conhecimento eaprendizagem, para discutir fatores que condicionam a transferência de conhecimento e aprendizagem por meio de programas de desenvolvimento de fornecedor. Uma framenork conceitual para melhoria do conhecimento é desenvolvida. Pesquisa empírica foi conduzida em 4 grandes organizações multinacionais, explorando como parceiros da cadeia de suprimentos podem melhor utilizar suas capacidades e facilitar a transferência de conhecimento através desses programas. Como resultados do estudo, foram identificados fatores organizacionais e relacionais que afetam o sucesso da transferência do conhecimento.

A tualmente existe uma vasta literatura em estudos organizacionais e de administração sobre como 0 aprendizado acontece em organizações. As teorias de aprendizado tradicionalmente focaram a aprendizagem do indivíduo, mas em anos 
recentes houve um salto para verificar se as organizações podem aprender elas mesmas. Os proponentes da aprendizagem organizacional advogam que apesar de serem os indivíduos que passam pelo processo de aprendizagem, ele acontece dentro do contexto proporcionado pela organização (ARGY RIS; SCHO N, 1978). A organização como um todo continuamente acumula conhecimento por meio dos indivíduos que geram e transferem novas soluções (NONAKA; TAKEUCHI, 1995). Esse conhecimento acumulado pode, então, sobreviver à partida dos indivíduos e nutrir novos funcionários.

A transferência de conhecimento entre dois ou mais atores (indivíduos e organizações) em um ambiente organizacional pode ser definida como um processo pelo qual o conhecimento de um ator é adquirido por outro (GIANNAKIS, 2008). O corre quando um ator é afetado por esse saber e aprende com experiências de outro(s) ator(es) por meio de rotinas e capacidades. Em uma organização, esse processo pode acontecer de diferentes maneiras, tais como interação de pessoal, processos de patente, publicações e outras. Conhecimento não é simplesmente agregação de informação, mas éinformação associada a um significado dentro de um processo de interpretação individual e/ ou organizacional. É desenvolvido com um propósito específico para se adquirir uma habilidade ou competência especial.

Giannakis (2008) define os quatro estágios para transferência de conhecimento, que são apresentados no Quadro 2.

- Aquisição de informação de um ator externo.

- Comunicação dessa informação para 0 restante da organização.

- (os 2 primeiros estágios se referem a quem e como vários atores adquirem e passam informação que os faz se interessarem por fazê-lo, com quem eles compartilham e quais os aspectos compartilhados).

- Aplicação, e então adoção e retenção da informação na organização (ou seja, na forma de implementação de um modelo de boa prática).

- Assimilação da informação. Esse estágio é indiscutivelmente 0 mais significativo da transferência de conhecimento à medida que representa 0 processo de aprendizado cumulativo que envolve mudança em habilidades e atitudes dos indivíduos e rotinas organizacionais como resultado direto do uso do conhecimento.

Quadro 2: Q uatro estágios para transferência de conhecimento

Fonte: Giannakis (2008).

Um aspecto importante de se tratar quando se fala em transferência de conhecimento é a identificação dos tipos de conhecimento. Entre as principais abordagens reconhecidas na literatura como referência teónica, uma classificação considera que existem basicamente dois tipos de conhecimento: explícito (ou codificado) e tácito. D e acordo com Nonaka e Takeuchi (1997), o conhecimento explícito éfacilmente transmissível por meio da linguagem formal, codificada e sistemática, e constitui a ponta do iceberg. Pode ser armazenado, por exemplo, em documentos, manuais, bancos de dados ou em outras mídias (HANSEN; NOHRIA;TURNEY, 1999). Caractenizam-se pelo conhecimento baseado em regras, procedimentos operacionais padronizados e num adequado registro de dados. Choo (2003) comenta que as empresas se beneficiam de certo nível de controle e eficiência operacional.

Giannakis (2008) apresenta um quadro em que diferencia os conhecimentos tácito e explícito, que está reproduzido no Quadro 3.

\begin{tabular}{|l|l|l|}
\hline & Tácito & Explícito \\
\hline Definição & $\begin{array}{l}\text { Know-how (saber } \\
\text { como), know what, } \\
\text { habilidades expres- } \\
\text { sas por meio de } \\
\text { performance }\end{array}$ & $\begin{array}{l}\text { Know-about (saber } \\
\text { o quê): compreender } \\
\text { fatos, teorias e } \\
\text { instruções }\end{array}$ \\
\hline $\begin{array}{l}\text { Qualidade, } \\
\text { velocidade } \\
\text { custo de } \\
\text { transferência }\end{array}$ & $\begin{array}{l}\text { Lento, custoso e } \\
\text { incerto }\end{array}$ & $\begin{array}{l}\text { Rápido, talvez } \\
\text { custoso, acurado }\end{array}$ \\
\hline Difusão & Difícil de transmitir & Fácil de transmitir \\
\hline Residência & $\begin{array}{l}\text { Informação geral, } \\
\text { experiências e } \\
\text { memória }\end{array}$ & $\begin{array}{l}\text { Livros, documentos, } \\
\text { bancos de dados, } \\
\text { manuais }\end{array}$ \\
\hline
\end{tabular}

Q uadro 3: Classificação do conhecimento

Fonte: $\mathrm{G}$ iannakis (2008).

O estudo de caso múltiplo realizado por Giannakis (2008) em quatro grandes organizações daInglaterra- uma empresa de serviços financeiros, uma indústria farmacêutica, uma empresa de telecomunicações e uma operadora de aeroporto - revelou que os gerentes consideram que compartilhamento de informação não acontece como eles gostariam. Nos quatro casos estudados, o meio mais comum pelo qual dados, informações e conhecimento codificado (explícito) se move é o e-mail e o telefone.

Num primeiro passo da pesquisa, foram analisados os quatro estágios da transferência de conhecimento nas empresas estudadas. Para os processos de Aquisiçãoe Commicacãa quatro variáveis foram analisadas: nível de compartilhamento das redes de informação, quão frequente é o compartilhamento de informação, o tipo de conhecimento compartilhado e os meios pelos quais o conhecimento é compartilhado. Foi identificado maior nível de processos de aquisição e comunicação nas organizações farmacêuticas e na operadora de aeroporto. Com relação ao estágio Aplicação os entrevistados foram solicitados a identificar se boas práticas foram desenvolvidas ou transferidas por meio dos SD programmes e como eles as implementaram. Em todos os programas, as melhores práticas transferidas via SD programmes foram: benchmarking, uso de survess(questionários) para medir performance, esaurange a organização de workshops de treinamento. D ocumentos referência foram considerados relevantes apenas na indústria farmacêutica. Para 0 estágio Assimilaçãa observou-se que é difícil se ter acesso ao grau de assimilação de conhecimento sendo transferido; porém, a indústria farmacêutica e a operadora de aeroporto parecem mais bem-sucedidas nesse sentido. 
O segundo passo da pesquisa de Giannakis (2008) foi a análise dos fatores condicionantes da transferência de conhecimento nas empresas, que são:

- Processos de interação - canais formais de interação entre parceiros afetam fortemente a velocidade e facilidade de transferência de conhecimento. Na financeiranão havialinks diretos com fornecedor. Na farmacêutica ena operadora de aeroporto times de D esenvolvimento de Fornecedor foram designados para agir como gatdkeepas (guardiões) para a transmissão de informação.

- Aprendizado e ensinamento formal - um aspecto chave do sucesso, que era limitado nas empresas de telecomunicações e financeira, foi que o processo de transferência de conhecimento não era baseado na filosofia do "aprendendo para fazer" (leamingbydaing. As outras duas organizações, por sua vez, tinham esquemas mais bem estabelecidos de treinamento, em que vánios gerentes de ambos os SD programmes participavam de workshops numaárea de desenvolvimento específica.

- Habilidades dos indivíduos - nível de expetisedos indivíduos participantes. Percebeu-se que nos quatro programas os gerentes não tinham conhecimento suficiente de seus processos.

- A tmosfera no programa - relaciona-se à importância de as empresas envolvidas terem uma parceria forte, entendimento mútuo e haver suporte entre parceiros.

Mohr e Nevin (1990) destacam uma série de dimensões de comunicação que podem variar segundo os diferentes tipos de relacionamento por canais. Essasfacetas de comunicação compreendem a frequência, a direção, a modalidade e o conteúdo. O s autores dividiram os modos de comunicação em formais e informais. São comunicações formais as que têm por escrito e giram em torno de algum aspecto estrutural das empresas (ex. avaliações anuais de desempenho). As informais são mais espontâneas e costumam envolver contato face a face (BOY LE; ALWITT, 1999). Esses autores apontam também possíveis meios de comunicação entre empresas: telefone, entrevista face a face, serviço postal expresso (ex.: FedEx), serviço postal tradicional, seminários, feiras comerciais e ligação por computador.

O s elementos apresentados neste tópico são importantes para dar suporte à pesquisa realizada neste trabalho.

\subsection{Cadeia de autopeças de reposição}

O segmento de reposição deautopeças, também conhecido como attemarke, é bastante importante para o setor automobilístico. Segundo o SINDIPEÇAS (Sindicato das Indústrias de Autopeças), em 2007 o segmento de aftemarket foi responsável por $12,5 \%$ do faturamento da indústria automobilística nacional (US $\$ 4,5$ bilhões dos US $\$ 36$ bilhões faturados).

O setor automobílístico é composto por montadoras de veículos de diferentes tipos: automóveis e veículos comerciais leves, motocicletas, caminhões e ônibus, e máquinas agrícolas. O Q uadro 4 apresenta relação de montadoras existentes no Brasil atualmente

\begin{tabular}{|c|c|c|}
\hline $\begin{array}{l}\text { Tipo de } \\
\text { Veículo }\end{array}$ & $\begin{array}{l}\text { Quantidade de } \\
\text { montadoras }\end{array}$ & Montadoras \\
\hline $\begin{array}{l}\text { Automóveis } \\
\text { e comerciais } \\
\text { leves }\end{array}$ & 21 & $\begin{array}{l}\text { Agrale, Brax (Lombini), } \\
\text { Chamonix, Citroën, Fiat, } \\
\text { Ford, G eneral Motors, } \\
\text { Honda, Hyundai, Karmann- } \\
\text { Guia, Mahindra, Mercedes- } \\
\text { Benz, Mitsubishi Motors, } \\
\text { Nissan, O bvio!, PSA } \\
\text { Peugeot Citroën, Renault, } \\
\text { TAC, Toyota, Troller (Ford) } \\
\text { e Volkswagen. }\end{array}$ \\
\hline Motocicletas & 15 & $\begin{array}{l}\text { BMW, D afra, FYM, Garini, } \\
\text { Grupo Izzo, Haobao, } \\
\text { Harley-D avidson, Honda, } \\
\text { Kasinski, MVK, Motor Z, } \\
\text { Sundown, Suzuki, Traxx e } \\
\text { Yamaha. }\end{array}$ \\
\hline $\begin{array}{l}\text { Caminhões e } \\
\text { ônibus }\end{array}$ & 10 & $\begin{array}{l}\text { Agrale, Ford caminhões, } \\
\text { Hyundai, International, } \\
\text { Iveco, Mercedes-Benz, } \\
\text { Scania, Volare, VW } \\
\text { caminhões e Volvo. }\end{array}$ \\
\hline $\begin{array}{l}\text { Máquinas } \\
\text { agrícolas }\end{array}$ & 8 & $\begin{array}{l}\text { AGCO, Agrale, Caterpillar, } \\
\text { CNH, John D eere, } \\
\text { Komatsu, Valtra e Volvo. }\end{array}$ \\
\hline
\end{tabular}

Q uadro 4: Montadoras existentes no Brasil em 2008

Fonte: www.automotivebusiness.com.br.

D entro da indústria automobilística, as montadoras são conhecidas como O EM (Orignal EquipmentManufactuning. Esse grupo de empresas foi responsável por 87,5\% do faturamento da indústria automotiva em 2007. As peças produzidas pelas montadoras geralmente são destinadas à produção de veículos $0 \mathrm{KM}$ ou às concessionárias para reposição.

As montadoras determinam a quantidade de veículos que será produzida e por consequência determinam o que será produzido nas indústrias de autopeças voltadas para fornecer às montadoras. Algumas indústrias do setor de autopeças optam por trabalhar fornecendo para as montadoras. As indústrias de autopeças voltadas para O E M garantem uma produção constante e programada durante 0 ano, porém, com uma rentabilidade menor, em comparação com o segmento de reposição ou attemarke. 0 setor de aftemarkeproduz peças para reposição que são vendidas fora da rede de concessionárias. E sse setor não possui uma previsibilidade na demanda de mercado, o que obriga as indústrias que atendem a esse mercado a aceitarem e se adaptarem às variações nas quantidades vendidas mensalmente durante 0 ano. Essa variação ocorre em função da necessidade do proprietário do veículo ou consumidor final de realizar manutenção corretiva ou preventiva de seu veículo. É interessante salientar que algumas peças comercializadas nas concessionárias são idênticas às comercializadas no mercado de reposição ou attemarke, sendo inclusive produzidas pelo mesmo fabricante. Nesses casos, somente a embalagem é diferente, além do preço, que éinferior ao da concessionária. 
Para que as peças do mercado de aftemrarkecheguem até 0 aplicador, que é o reparador automotivo, utiliza-se a figura do distribuidor. 0 distribuidor recebe a visita do representante de vendas da indústria de autopeças. Uma das atribuições do representante é repassar à indústria o comportamento do mercado. 0 distribuidor pode ser um atacadista, que comercializa todos os produtos do segmento automotivo - elétricos, mecânicose atétapeçaria- ou pode ser um especialista que comercializa somente um desses tipos de produto.

Os distribuidores possuem vendedores na rua, que são conhecidos como representantes da distribuidora, que visitam os aplicadores ou reparadores automotivosespalhados pelo Brasil. Eles coletam as sensibilidades expressadas informalmente pelos aplicadores sobre o produto e sobre as necessidades de mercado. Algumas vezes, os aplicadores passam essas informações diretamente para a indústria, outras vezes passam para o responsável da distribuidora, que pode repassá-las para a indústria. 0 distribuidor define as quantidades a serem compradas da indústria com base nas informações do mercado, repassadas pelo representante de vendas da distribuidora. Essas informações ajudam a distribuidora a nortear suas estratégias de venda e de compra de peças automotivas do mercado de reposição ou aftemmarket.

$\mathrm{O}$ aplicador ou reparador automotivo necessita ter um conhecimento técnico e holístico do mercado de autopeças. Ele coloca em prática os conhecimentos adquiridos e as informações passadas pela indústria, procurando, dessa forma, alcançar seu objetivo: fazer o proprietário do veículo se sentir satisfeito. A Figura 3 mostra uma representação dos elos que compõem a cadeia de autopeças de reposição ou aftemarke. nos mais diversos segmentos a exemplo de embalagens, papel alumínio, utensílios domésticos, e na construção civil. Extrudados servem basicamente a aplicações industriais diversas como elementos componentes de partes mecânicas na indústria de autopeças, na indústria de bens de consumo como bicicletas, utensilios domésticos, elementos estruturais e decorativos na construção civil. Fundidos e forjados têm aplicação na indústria de autopeças, em elementos decorativos, obras de arte, acessórios de vestuário, entre outras utilizações.

O segmento de extrudados com aplicação na construção civil no Brasil é dominado basicamente por grandes empresas multinacionais produtoras do alumínio primário e alguns extrusores de médio porte. Essa cadeia produtiva inicia-se basicamente na entrega dos tarugos de alumínio nas unidades de extrusão - processo de transformação mecânica no qual o tarugo é forçado a fluir através do orifício de uma matriz (ferramenta) transformando-se em perfil, produto acabado da extrusão. Esse processo é efetuado por prensas hidráulicas com capacidade de força variando de 400 até 15.000 t. Prensas entre 1.200 e 2.400 toneladas são usadas para produzir a maior parte dos extrudados de alumínio produzidos no mundo.

0 perfil recém-extrudado, possui acabamento natural pouco atraente - e normalmente necessita receber um acabamento antes de ser manufaturado e transformado no produto a que se destina - portas, portões, janelas, box, ou outro. Esse processo de acabamento é efetuado ou pelos próprios produtores do perfil ou por empresas especializadas - os beneficiadores. A partir desse processo, o perfil está pronto para ser manufaturado, recebendo outros perfis, cortes, montagens e

Montadora de
veículos $\leftrightarrow \begin{gathered}\text { Indústria de } \\ \text { autopeças }\end{gathered} \leftrightarrow \begin{gathered}\text { Distribuidor de } \\ \text { autopeças }\end{gathered} \leftrightarrow \stackrel{\begin{array}{c}\text { Aplicador das } \\ \text { autopeças }\end{array}}{\leftrightarrow} \leftrightarrow \begin{gathered}\text { Cliente final dono } \\ \text { do veículo }\end{gathered}$

Figura 3: Representação cadeia de autopeças de aftemark‡

Fonte: Elaborada pelos autores.

\subsection{Cadeia de extrudados de alumínio para construção civil}

0 alumínio é o metal mais jovem a ser utilizado em escala industrial, apesar de representar o terceiro elemento mais abundante na crosta terrestre. 0 Brasil possui a terceira maior reserva de bauxita do planeta sendo esse minério o mais importante para a produção do alumínio.

Entre as diversas aplicações do alumínio, no âmbito nacional, destacam-se os semimanufaturados, que se dividem em laminados, extrudados, fundidos e forjados. Laminados servem basicamente à produção de lâminas em seus diversos tipos de aplicação tais como folhas, chapas, telhas e fachadas para uso acessórios específicos, transformando-se em esquadrias - definição genérica de toda estrutura destinada a fechar um vão produto final destinado à construção civil. Esse processo é realizado por serralheiros (as de pequeno porte), fábricas de esquadrias (as de médio porte) ou indústrias de esquadrias ou padronizados (as de maior porte). Neste trabalho iremos denominá-los aplicadores, independentemente do porte.

Portanto, nessa cadeia, a partir do produtor do perfil (extrusor), agregam-se diversas empresas, normalmente PMEs, como beneficiadores, aplicadores e fabricantes de acessórios. A Figura 4 representa a cadeia de alumínio extrudado destinado à construção civil.

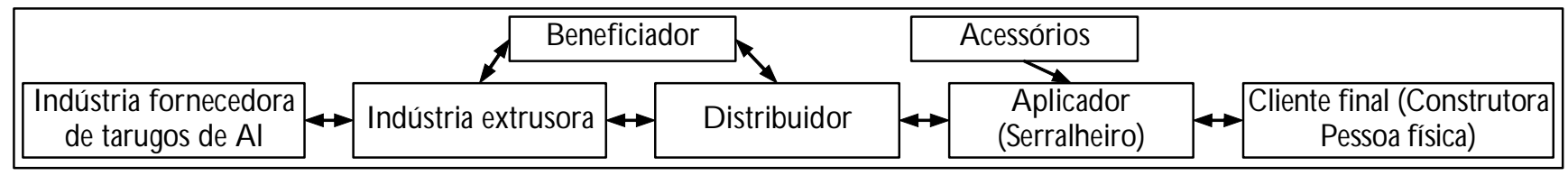

Figura 4: Representação da cadeia de alumínio extrudado destinado à produção de perfis a serem utilizados na construção civil

Fonte: Elaborada pelos autores.

LCONTEXTUS Revista Contemporânea de Economia e G estão. V0l.8 - № 1 - jan/ jun/ 2010. (33-44).


O quadro 5 apresenta uma comparação das características dos elos das cadeias pesquisadas, em termos de quantidade de empresas existentes no Brasil.

\begin{tabular}{|c|c|}
\hline ALUMÍN IO EXTRUDADO \\
PARA CONST RUÇÃO CIVIL & AUTOPEÇAS \\
\hline $\begin{array}{c}\text { Poucas Indústrias (domínio de } \\
2 \text { a } 3 \text { de grande extrusoras) e } \\
\text { algumas dezenas médias e de } \\
\text { pequeno porte. }\end{array}$ & Várias Indústrias. \\
\hline $\begin{array}{c}\text { Poucos distribuidores, a } \\
\text { maioria exclusivos ou próprios } \\
\text { no caso das grandes } \\
\text { extrusoras, ou independentes } \\
\text { para atender extrusores de } \\
\text { menor porte. }\end{array}$ & $\begin{array}{c}\text { Vários } \\
\text { indribuidores }\end{array}$ \\
\hline $\begin{array}{c}\text { indendentes. } \\
\text { poucos aplicadores de grande } \\
\text { e milhares de pequeno porte. }\end{array}$ & $\begin{array}{c}\text { Há milhares de } \\
\text { aplicadores de } \\
\text { pequeno porte. }\end{array}$ \\
\hline
\end{tabular}

Q uadro 5: Comparativo das características dos elos das cadeias pesquisadas

Fonte: Elaborado pelos autores.

\section{METODOLOGIA DE PESQUISA}

Esta pesquisa teve natureza exploratória. A pesquisa exploratória é particularmente útil quando o pesquisador dispõe de muito poucas informações. Dito de outro modo, os planos exploratórios são para o pesquisador que não sabe muito. São orientados para a descoberta. Assim, são planos que não têm a intenção de testar hipóteses (HAIR etal., 2005). Pode-se considerar que os processos de transferência de conhecimento entre os elos das cadeias brasileiras de autopeças aftemarkete de extrudados de alumínio para a produção de perfis para a construção civil são pouco conhecidos, não tendo sido encontrados estudos voltados para o seu mapeamento. Busca-se neste estudo obter percepções de profissionais que atuam nos elos das cadeias com relação ao problema de pesquisa definido, utilizando-se, portanto, de método de pesquisa qualitativo.

Foram realizadas entrevistas semiestruturadas com profissionais de empresas que fazem parte das refenidas cadeias de suprimentos. As entrevistas foram realizadas pessoalmente, ou por telefone, e as respostas foram transcritas de forma mais fiel possível.
O roteiro de entrevista utilizado é apresentado no Q uadro 6.

1. Você percebe que os elos da cadeia de autopeças

(alumínio) aproveitam o conhecimento dos outros elos da cadeia? Como ocorre esse processo?

2. Q uais os principais conhecimentos aproveitados?

3. Q uais os canais/ meios de comunicação utilizados no processo de transferência de conhecimento?

Q uadro 6: Roteiro de entrevistas utilizado nesta pesquisa Fonte: Elaborado pelos autores.

D epois de finalizadas as entrevistas e suas transcrições, foi realizada análise das respostas, procurando-se sintetizá-las, e expressando sua ideia central. Finalmente, foi efetuada consolidação das respostas sintéticas, por elo de cada cadeia.

\section{ANÁLISE DOSRESULTADOS}

A pesquisa de campo consistiu da realização de 15 entrevistas, sendo $9 \mathrm{com}$ participantes da cadeia de autopeças attemarke e 6 com participantes da cadeia de extrudados de alumínio para a construção civil. 0 Quadro 7 mostra a distribuição dos entrevistados, segundo o elo da cadeia a que pertence.

\begin{tabular}{|l|c|c|c|c|c|}
\hline & \multicolumn{2}{|c|}{ Autopeças } & \multicolumn{2}{|c|}{ Alumínio } & Total \\
\hline Indústria & 3 & $\begin{array}{c}3 \text { gerentes de } \\
\text { vendas } \\
\text { reposição }\end{array}$ & 3 & $\begin{array}{c}1 \text { gerente de } \\
\text { marketing e 2 } \\
\text { analistas de } \\
\text { mercado }\end{array}$ & 6 \\
\hline Distribuidor & 3 & $\begin{array}{c}2 \text { compradores } \\
\text { e 1 } \\
\text { proprietário }\end{array}$ & 2 & Representantes & 5 \\
\hline Aplicador & 3 & $\begin{array}{c}3 \text { proprietários } \\
\text { que atuam } \\
\text { como } \\
\text { reparador }\end{array}$ & 1 & $\begin{array}{c}\text { Projetista de } \\
\text { perfis da } \\
\text { indústria ligado } \\
\text { diretamente a } \\
\text { diversos } \\
\text { aplicadores }\end{array}$ & 4 \\
\hline Total & 9 & 6 & and \\
\hline
\end{tabular}

Q uadro 7: Entrevistados por cadeia e elo a que pertence Fonte: Elaborado pelos autores. 
O quadro 8 apresenta síntese das respostas obtidas nas entrevistas.

\begin{tabular}{|c|c|c|c|c|c|c|}
\hline \multicolumn{4}{|c|}{ AUTOPEÇAS } & \multicolumn{3}{|c|}{ ALUMÍNIO } \\
\hline & $\begin{array}{c}\text { 10 Elos aproveitam } \\
\text { o conhec. entre si? } \\
\text { Como? }\end{array}$ & $\begin{array}{c}2^{0} \text { Quais } \\
\text { conhecimentos? }\end{array}$ & $3^{\circ}$ Canais / meios? & $\begin{array}{l}11^{0} \text { Elos } \\
\text { aproveitam o } \\
\text { conhec. entre } \\
\text { si? Como? }\end{array}$ & $\begin{array}{c}2^{0} \text { Quais } \\
\text { conhecimentos? }\end{array}$ & $\begin{array}{c}3^{0} \text { Canais / } \\
\text { meios? }\end{array}$ \\
\hline Ind. & $\begin{array}{l}\text { Há aproveitamento } \\
\text { parcial, com } \\
\text { necessidade de } \\
\text { filtragem. }\end{array}$ & $\begin{array}{l}\text { Inovações técnicas de } \\
\text { produto, alguns } \\
\text { fornecem dados } \\
\text { sobre a concorrência. }\end{array}$ & $\begin{array}{c}\text { Treinamento } \\
\text { seguido de } \\
\text { confraternização, } \\
\text { pesquisa de } \\
\text { satisfação com } \\
\text { distribuidores e } \\
\text { aplicadores, contato } \\
\text { com os } \\
\text { representantes do } \\
\text { distribuidor, via } \\
\text { fone ou e-mail e } \\
\text { jornalzinho (todos } \\
\text { não estruturados). }\end{array}$ & $\begin{array}{c}\text { Há } \\
\text { aproveitament } \\
\text { o significativo, } \\
\text { principalmente } \\
\text { de informações } \\
\text { que recebe do } \\
\text { distribuidor. } \\
\text { Também serve } \\
\text { como } \\
\text { multiplicador } \\
\text { de informações } \\
\text { repassando aos } \\
\text { serralheiros e } \\
\text { fabricantes dos } \\
\text { componentes. }\end{array}$ & $\begin{array}{l}\text { Solicitação de } \\
\text { desenvolvimen } \\
\text { to de produtos, } \\
\text { necessidades } \\
\text { de mercado e } \\
\text { políticas sociais } \\
\text { e ambientais. }\end{array}$ & $\begin{array}{l}\text { Pesquisa de } \\
\text { mercado, } \\
\text { informações de } \\
\text { gerentes e } \\
\text { técnicos via e- } \\
\text { mail ou fone, } \\
\text { catálogo, } \\
\text { treinamento } \\
\text { seguido de } \\
\text { confrater- } \\
\text { nização. }\end{array}$ \\
\hline Dist. & $\begin{array}{l}\text { Sim, aproveita } \\
\text { informações sobre } \\
\text { necessidades de } \\
\text { mercado e repassa à } \\
\text { indústria, não há } \\
\text { troca de indústria } \\
\text { para indústria, seria } \\
\text { necessário maior } \\
\text { contato da indústria } \\
\text { com o distribuidor, } \\
\text { há troca da pequena } \\
\text { indústria e não há na } \\
\text { grande indústria } \\
\text { para com o } \\
\text { distribuidor. }\end{array}$ & $\begin{array}{l}\text { Qualidade do } \\
\text { produto percebida } \\
\text { pelo mercado, a } \\
\text { impressão de que } \\
\text { opiniões não são bem } \\
\text { aceitas pela indústria } \\
\text { e de que o elo de } \\
\text { relaciona-mento entre } \\
\text { o distribuidor e a } \\
\text { Autoelétrica é maior } \\
\text { do que com a } \\
\text { indústria. }\end{array}$ & $\begin{array}{c}\text { Visita dos } \\
\text { representantes de } \\
\text { venda da } \\
\text { distribuidora, } \\
\text { contato via fone, } \\
\text { via e-mail, eventos } \\
\text { que objetivam } \\
\text { reunir a cadeia; } \\
\text { percebemos que há } \\
\text { uma queixa para } \\
\text { não existir um canal } \\
\text { formal para isso, e a } \\
\text { impressão de que as } \\
\text { informações são } \\
\text { pouco utilizadas. }\end{array}$ & $\begin{array}{c}\text { Há } \\
\text { aproveitament } \\
\text { o e troca das } \\
\text { informações } \\
\text { principalmente } \\
\text { com a indústria } \\
\text { e com os } \\
\text { demais } \\
\text { distribuidores. }\end{array}$ & $\begin{array}{l}\text { Informações } \\
\text { de caráter } \\
\text { técnico e } \\
\text { estratégias de } \\
\text { atuação por } \\
\text { parte da } \\
\text { indústria, e de } \\
\text { relações } \\
\text { comercias e de } \\
\text { mercado com } \\
\text { outros } \\
\text { distribuidores. }\end{array}$ & $\begin{array}{l}\text { E-mails, } \\
\text { telefones e } \\
\text { reuniões } \\
\text { esporádicas. }\end{array}$ \\
\hline Aplic. & $\begin{array}{l}\text { As melhorias e } \\
\text { correções dos } \\
\text { produtos não são } \\
\text { bem disseminadas, } \\
\text { relacionam troca de } \\
\text { conhecimento com } \\
\text { a marca forte do } \\
\text { produto e há um } \\
\text { forte vínculo } \\
\text { profissional entre as } \\
\text { Autoelétricas } \\
\text { concorrentes. }\end{array}$ & $\begin{array}{l}\text { Passar as informações } \\
\text { para as indústrias e } \\
\text { fazer com que elas as } \\
\text { transformem em } \\
\text { conhecimento, } \\
\text { fornecer informações } \\
\text { de que as indústrias } \\
\text { devem lançar e } \\
\text { conhecer todos os } \\
\text { tipos de produtos da } \\
\text { indústria disponíveis } \\
\text { para melhor atender o } \\
\text { cliente da } \\
\text { Autoelétrica. }\end{array}$ & $\begin{array}{l}\text { Via fone, internet, } \\
\text { palestras, cursos, } \\
\text { reunião com } \\
\text { colegas de outras } \\
\text { Autoelétricas, } \\
\text { catálogos, mala } \\
\text { direta e jornal. }\end{array}$ & $\begin{array}{c}\text { Há } \\
\text { aproveitament } \\
\text { o da indústria e } \\
\text { de outros } \\
\text { fornecedores. }\end{array}$ & $\begin{array}{c}\text { Técnicas tais } \\
\text { como } \\
\text { desenhos }\end{array}$ & E-mails \\
\hline
\end{tabular}

Q uadro 8: Síntese das respostas obtidas por elo das cadeias

Fonte: Elaborado pelos autores. 
Com base na análise das respostas foram elaboradas as Figuras 5 e 6 . As Figuras indicam o nível de transferência de conhecimento entre os elos das duas cadeias produtivas pesquisadas, utilizando-se de uma nota que varia entre 1 e 5 , atribuída à questão 1 do roteiro de entrevista "Você percebe que os elos da cadeia de autopeças (alumínio) aproveitam o conhecimento dos outros elos da cadeia?". Também são apresentados nas Figuras resultados relativos às duas outras questões "Quais os conhecimentos Aproveitados?" e "Canais/ meios utilizados?" Nesse caso, foi indicado o nível de estruturação dos canais utilizados. O s canais mais estruturados são catálogos, treinamentos, manuais e outros. Os canais menos estruturados são mais informais - confratemizações, conversas telefônicas, e-mails, e outros.

\subsection{Análise dos resultados para a cadeia de autopeças}

Com base no Quadro 8 e na Figura 5, é possível identificarmos:

- No caso das indústrias de autopeças podemos afirmar que há um aproveitamento parcial de informações/ conhecimentos nas relações entre os elos estudados. As notas atribuídas para a questão "aproveitamento do conhecimento" entre indústria e distribuidor são 2,5.

- O bserva-se baixa troca entre 0 aplicador eaindústria; porém, há alta transferência entre aplicador e distribuidor.

- Constatou-se que há troca de informações do distribuidor com a indústria; porém, observou-se que o distribuidor deseja que indústria se aproxime mais. Os en-

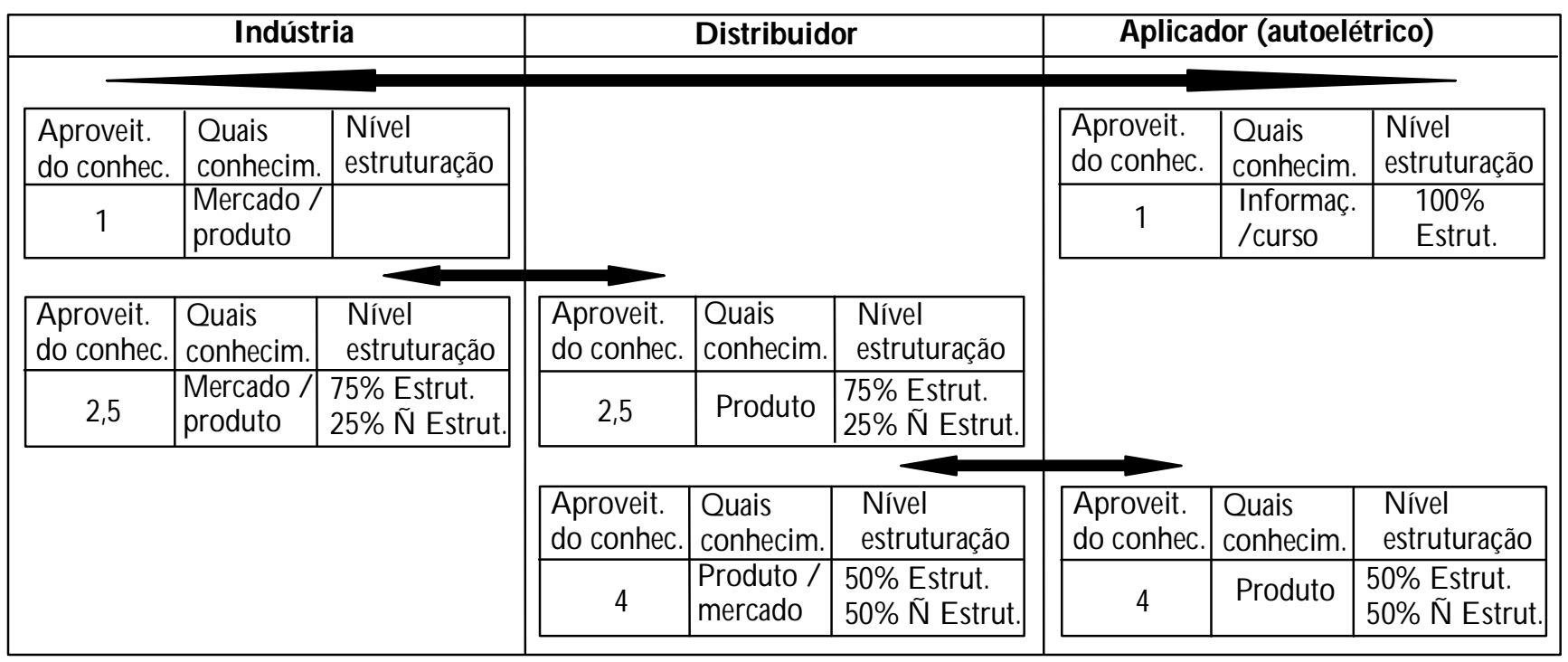

Figura 5: Demonstrativo da transferência da informação e do conhecimento na cadeia de autopeças aftemarke

Fonte: Elaborada pelos autores.

\begin{tabular}{|c|c|c|c|c|c|c|c|c|}
\hline \multicolumn{3}{|c|}{ Indústria } & \multicolumn{3}{|c|}{ Distribuidor } & \multicolumn{3}{|c|}{ Aplicador (autoelétrico) } \\
\hline $\begin{array}{l}\text { Aproveit. } \\
\text { do conhec. }\end{array}$ & \begin{tabular}{l|} 
Quais \\
conhecim.
\end{tabular} & \begin{tabular}{l|} 
Nível \\
estruturação
\end{tabular} & & & & \multirow{2}{*}{\begin{tabular}{|c|}
$\begin{array}{l}\text { Aproveit. } \\
\text { do conhec. }\end{array}$ \\
3 \\
\end{tabular}} & \multirow{2}{*}{$\begin{array}{l}\text { Quais } \\
\text { conhecim. } \\
\text { Inform. } \\
\text { Técnicas }\end{array}$} & \multirow{2}{*}{\begin{tabular}{|l|}
$\begin{array}{l}\text { Nível } \\
\text { estruturação }\end{array}$ \\
$90 \%$ Estrut. \\
$10 \%$ N Estrut.
\end{tabular}} \\
\hline 3 & $\begin{array}{l}\text { Inform. } \\
\text { Técnicas }\end{array}$ & $\begin{array}{l}85 \% \text { Estrut. } \\
15 \% \text { N E strut. }\end{array}$ & & & & & & \\
\hline \begin{tabular}{|l|} 
Aproveit. \\
do conhec.
\end{tabular} & $\begin{array}{l}\text { Quais } \\
\text { conhecim. }\end{array}$ & $\begin{array}{l}\text { Nível } \\
\text { estruturação }\end{array}$ & $\begin{array}{l}\text { Aproveit. } \\
\text { do conhec. }\end{array}$ & $\begin{array}{l}\text { Quais } \\
\text { conhecim. }\end{array}$ & $\begin{array}{l}\text { Nível } \\
\text { estruturação }\end{array}$ & & & \\
\hline \multirow[t]{3}{*}{4} & $\begin{array}{l}\text { Inform. } \\
\text { Mercado }\end{array}$ & $\begin{array}{l}20 \% \text { Estrut. } \\
80 \% \text { N Estrut. }\end{array}$ & 4 & \begin{tabular}{|l} 
Inform. \\
Técnicas
\end{tabular} & $\begin{array}{l}60 \% \text { Estrut. } \\
40 \% \text { N Estrut. }\end{array}$ & & & \\
\hline & & & \begin{tabular}{|l|} 
Aproveit. \\
do conhec.
\end{tabular} & $\begin{array}{l}\text { Quais } \\
\text { conhecim. }\end{array}$ & $\begin{array}{l}\text { Nível } \\
\text { estruturação }\end{array}$ & $\begin{array}{l}\text { Aproveit. } \\
\text { do conhec. }\end{array}$ & \begin{tabular}{|l|} 
Quais \\
conhecim.
\end{tabular} & $\begin{array}{l}\text { Nível } \\
\text { estruturação }\end{array}$ \\
\hline & & & 2 & & $\begin{array}{l}50 \% \text { Estrut. } \\
50 \% \text { N Estrut. }\end{array}$ & 1 & $\begin{array}{l}\text { Inform. } \\
\text { Técnicas }\end{array}$ & $\begin{array}{l}60 \% \text { Estrut. } \\
40 \% \text { N Estrut. }\end{array}$ \\
\hline
\end{tabular}

Figura 6: Demonstrativo da transferência da informação e do conhecimento na cadeia de extrudados

Fonte: Elaborada pelos autores. 
trevistados declararam que a indústria não se interessa quando o distribuidor manifesta sua opinião sem ser consultado.

- Nas entrevistas, verificou-se que não há transferência de indústria para indústria de autopeças.

- O bservou-se que os aplicadores de autopeças consideram que informações provenientes da indústria se perdem com os ruídos da transmissão e eles relacionam empresa que transmite bem as informações (catálogo, cursos, lançamento, entre outros meios) com marca forte no mercado. Esses ruídos são supridos pelo contato entre os aplicadores concorrentes, ou seja, eles trocam informações entre si, constatando, assim, que entre eles há um bom relacionamento e uma boa troca de informações. 0 aplicador percebe que quanto mais ele conhecer os produtos de uma indústria de autopeças melhor ele irá atender o seu cliente.

- O bserva-se que na relação indústria/ distribuidor predomina 0 envio de informações estruturadas (75\%), enquanto na relação distribuidor/ aplicador 50\% das informações enviadas são não estruturadas.

- Apesar de haver a transferência de informações sobre produto (inovação), predomina a transferência de informações sobre necessidades de mercado.

\subsection{Análise dos resultados para a cadeia de extrudados de alumínio}

- No caso das indústrias do segmento de extrudados, podemos dizer que há um aproveitamento mais efetivo das informações/ conhecimentos nas relações entre os elos estudados, principalmente de informações provenientes do distribuidor, elo de contato com o mercado e consumidor de seus produtos; essa indústria pode também utilizar o distribuidor como um disseminador de suas informações de volta ao mercado. As notas atribuídas para a questão "aproveitamento do conhecimento" entre indústria e distribuidor são 4.

- Há transferência significativa entre aplicador e indústria (notas 3), o que se deve ao fato de haver aplicadores de grande porte.

- A transferência de informações dos distribuidores para os aplicadores é maior em relação aos pequenos aplicadores, sendo que no caso dos médios e grandes aplicadores esse papel é desempenhado pela indústria diretamente. A recíproca é verdadeira também nesses casos.

- As informações transferidas envolvendo os aplicadores são de caráter técnico na grande maioria das vezes; porém, a indústria também se preocupa em transferir informações mercadológicas e de caráter socioambiental.

- No caso do distribuidor do segmento de extrudados, há troca de informações principalmente com as indústrias e os outros distribuidores do segmento; nesse segmento são trocadas informações de caráter técnico e sobre necessidades de mercado.
- Vale salientar que no caso de extrudados os distribuidores pesquisados são exclusivos e, portanto, a relação é mais intensa e com contratos jurídicos formalizados.

- No caso dos aplicadores de extrudados, podemos dizer que há troca de informações com os demais elos da cadeia: os de maior porte, principalmente com a indústria (que define os novos produtos); os de menor porte através dos distribuidores e com os fornecedores de acessórios e miscelâneas para confecção de esquadria. Essas informações são de caráter eminentemente técnico, com a transferência de desenhos de projetos, e ocorrem normalmente tendo o e-mail como ferramenta de transferência.

Válido para as duas cadeias:

- As informações são transmitidas da mesma formanos dois segmentos, ou seja, por meio de confraternizações, palestras, cursos ou treinamentos, catálogos, malas diretas, feiras, pesquisa de satisfação ou de mercado; pelo contato físico com técnicos, representantes ou gerentes do distribuidor; via fone, e-mail e jornal técnico publicitário.

\section{CONCLUSÃO}

Com base na pesquisa realizada, pode-se dizer que a cadeia de alumínio realiza mais troca de conhecimento do que a de autopeças. Na cadeia de autopeças predomina a troca de informações sobre necessidades de mercado, enquanto na de alumínio predomina a transferência de informações técnicas relativas a produto. Há equilíbrio na utilização de meios estruturados e não estruturados para a transferência de informações. Percebese, porém, que haveria possibilidades mais amplas de utilização dos diversos meios de transferência de informação apresentados na literatura.

Algumas hipóteses podem ser levantadas, a partir dos resultados obtidos, considerando-se os produtos comercializados por essas cadeias. Na cadeia de autopeças é possível que o know-how necessário à produção seja menos volátil e menos dependente de tecnologia, por tratar-se de mercado de reposição de produtos já desenvolvidos. Na cadeia de alumínio, devido à alta competitividade e à relativa facilidade de imitação mesmo considerando ferramentas inibidoras como patentes, por exemplo - , as empresas muitas vezes não conseguem desenvolver sozinhas rapidamente 0 know-how de que necessitam, e, portanto, o conhecimento extra deve ser adquirido de alguma outra forma. Essa hipótese pode-se fundamentar em Probst et al. (2002), para quem os mercados de conhecimento estão longe da perfeição, além de serem pouco transparentes, com "produtos" de difícil comparação, em que o comércio é frequentemente de ideias que têm potencial em vez daquelasjá capitalizadas e na capacidade de absorção das empresas descritas por Cohen e Leninthal (1990, p. 131), que observaram em suas pesquisas que a principal atividade de muitos departamentos de pesquisa e desenvolvimento não era o crescimento de novos procedimentos ou produtos, mas a aquisição inteligente de conhecimento externo. 0 utra hipótese é que por haver na cadeia 
do alumínio uma maior dependência entre a indústria extrusora e 0 aplicador de grande porte - que desenvolve a esquadria - a chamada "ligação entre produtos", em que há necessidade de formação de alianças estratégicas, com os participantes se comprometendo em metas comuns cooperando mutuamente na aquisição de know-how objetivando a redução de custos e riscos, o encurtamento do tempo até o mercado, o controle da movimentação do conhecimento possibilitando maior controle da concorrência (PROBST etal., 2002).

Deve-se considerar que o estudo consiste em etapa inicial de pesquisa mais ampla, eque possui como limitação principalmente o número relativamente reduzido de entrevistas.

\section{REFERÊNCIAS}

AHUJA, Gautam. The duality of collaboration: inducements and opportunities in the formation of interfirm linkages. Strategic Management Jaumal. Chichester. v. 21, Iss. 3, p. 317-343, Mar 2000. BOYLE, B.; ALWITT, L. 1999, Internet Use within the U.S. Plastics Industry, Industrial Marketing Management, 28, 327-341.

CHOPRA, S; MEIND L, P. Supply Chain Management: strategy, planning, and operation. 2nd ed. Upper Saddle River: Pearson/ Prentice Hall, 2004.

CHO O, Chun Wei. A Organização do Conheimenta como as arganiza ções usama informação para ciar significado, construir conheaimento e tomar deisões. São Paulo: SENAC, 2003.

COHEN, W.M; LEVINTHAL, D.A. Absorptive Capacity: A New Perspective on Learning and Innovation. Administrative Science Quartey, 35(1), p. 128-152.

CUNHA, V.; ZWICKER, R. Antecedentes do Relacionamento e da Performance em Empresas da Cadeia de Suprimentos: estruturação e aplicação de modelos de equações estruturais. RAE, São Paulo, v. 49, n. 2, 147-161, abr./ jun. 2009.

DYER, Jeffrey H.; HATCH, Nile W. Relation-specific capabilities and barriers to knowledge transfers: creating advantage through network relationships. Strategic Management Joumal, Chichester, v 27, p. 701, mai 2006.

DYER, Jeffrey H.; SING H, H. The Japanese Autombile Industry: Technology and Management at Nissan and Toyota. Harvard University, Council on East Asian Studies: Cambridge, MA, 1985

FLEURY, Afonso; FLEURY, Maria Tereza L. A arquitetura das redes empresariais como função do domínio de conhecimentos. In: AMATO NETO, João. Redes entre arganizaçóes São Paulo: ATLAS, 2005.

GIANNAKIS, Mihalis. Facilitating learning and knowledge transfer through supplier development. Supply Chain Management: an international journal. v. 13, n. 1, 2008

GULATI, R. Network location and learning: the influence of network resources and firm capabilities on alliance formation. Strategic Managenent Jamal. Chichester, v. 20, n. 5, 1991

G ULATI, Ranjay; NOHRIA, Nitin; ZAHEER, Akbar. Strategic networks. Strategic Management Joumal, Special Issue: Strategic Networks Chichester. v. 21, Iss. 3, p. 203-215, Mar 2000

HAIR, Joseph F.; BABIN, Barry; MONEY, Arthur, H.; SAMO UEL, Phillip. Fundamentos deMé́odos dePesquisa emAdministraçãa São Paulo: Artmed Editora, 2005

HANSEN, Morten T.; NO HRIA, Nithin; TIERNEY, Thomas. Wha's your Strategy for Managing Knowledge? Harvard Business Review, Massachussetts, p.106-116, 30 abr. 1999.
HOLM, D esiree Blankenburg; ERIKSSO N, Kent; JOHANSON, Jan. Creating value through mutual commitment to business network relationships. Strategic Management Joumal. Chichester. v. 20, Iss. 5, p. 467, May 1999.

MO HR, J. J; NEVIN, J. R. Communication strategies in marketing channels: a theoretical perspective. Jarmal of Marketing v. 54, n. 4, p. 36-51, 1990.

NO NAKA, I., TAKEUCHI, H. A Criação do Conheimento na Empre sa. São Paulo: Campus, 1997.

NOHRIA, Nittin. Is a Network Perspective a Useful Way of Studying O rganizations? In: NOHRIA, Nitin; ECCLES, Robert G. (O rg.) Networks and Organizations. Cambridge: Harvard Business School Press, Introd., p. 1-17, 1992.

PROBST, Gilbert; RAUB, Steffen; ROMHARDT, K ai. Gestão do Conheciomento. os elementos construtivos do sucesso. São Paulo: Artmed Editora, 2002.

Data de Submissão: 16/ 03/ 2009

Data de Aprovação: 22/ 06/ 2010 